\title{
ATRIBUTOS QUÍMICOS E FÍSICOS DE UM ARGISSOLO CULTIVADO COM Panicum maximum JACQ. CV. IPR-86 MILÊNIO, SOB LOTAÇÃO ROTACIONADA E ADUBADO COM NITROGÊNIO(1)
}

\author{
Patrícia Sarmento $^{(2)}$, Luis Roberto de Andrade Rodrigues ${ }^{(3)}$, Mara \\ Cristina Pessôa da Cruz ${ }^{(3)}$, Simony Marta Bernardo Lugão ${ }^{(4)}$, Fábio \\ Prudêncio de Campos ${ }^{(2)}$, José Frederico Centurion ${ }^{(3)} \&$ Manoel \\ Evaristo Ferreira ${ }^{(3)}$
}

\begin{abstract}
RESUMO
A avaliação dos atributos químicos e físicos do solo é necessária em estudos que exploram intensivamente os sistemas de pastejo. No presente trabalho, objetivou-se avaliar as variações nos atributos físicos e químicos de um Argissolo cultivado com capim-milênio, sob pastejo, no intervalo compreendido entre outubro/2001 e maio/2002, no quinto ano de aplicação sucessiva das seguintes doses de $\mathrm{N}$ : 0, 150, 300 e $450 \mathrm{~kg} \mathrm{ha}^{-1}$. Após os cinco anos de aplicação de $450 \mathrm{~kg} \mathrm{ha}^{-1} \mathrm{de} \mathrm{N}$, o teor de MO aumentou em $5 \mathrm{~g} \mathrm{dm}^{-3}$, o que resultou em aumento da CTC. No período de outubro/2001 a maio/2002 houve diminuição nos valores de pH e de V com a aplicação de N. A densidade do solo variou pouco com a adubação nitrogenada; a percentagem de microporos aumentou e a de macroporos diminuiu na camada de $0-5 \mathrm{~cm}$ com o aumento das doses de $\mathrm{N}$, mas a porosidade total permaneceu constante; e a resistência à penetração, quando o solo apresentava $90 \mathrm{~g} \mathrm{~kg}^{-1}$ de água, não foi afetada pelas doses de $\mathrm{N}$ e não foi restritiva ao crescimento das plantas.
\end{abstract}

Termos de indexação: densidade do solo, fertilidade do solo, porosidade do solo, resistência do solo à penetração.

\footnotetext{
(1) Parte da Tese de Doutorado apresentada pelo primeiro autor à Universidade Estadual Paulista - UNESP. Projeto financiado pelo IAPAR e apoiado pela UNESP/FCAV. Recebido para publicação em dezembro de 2005 e aprovado em agosto de 2007.

${ }^{(2)}$ Pesquisadores no Instituto de Zootecnia. Rua Heitor Penteado 56, Caixa Postal 60, CEP 13460-000 Nova Odessa (SP). E-mails: patricia@iz.sp.gov.br; fcpampos_99@yahoo.com

${ }^{(3)}$ Professores da Universidade Estadual Paulista - UNESP. Via de Acesso Prof. Paulo Donato Castellane s/n, CEP 14884-900 Jaboticabal (SP). E-mails: mcpcruz@fcav.unesp.br; jfcentur@fcav.unesp.br; evaristo@fcav.unesp.br

(4) Pesquisadora do Instituto Agronômico do Paraná - IAPAR. Caixa Postal 564, CEP 87701-970 Paranavaí (PR). E-mail: lugao@iapar.br
} 


\title{
SUMMARY: CHEMICAL AND PHYSICAL ATTRIBUTES IN AN ANFISOL CULTIVATED WITH PANICUM MAXIMUM JACQ. CV. IPR-86 MILÊNIO, UNDER ROTATIONAL STOCKING AND FERTILIZED WITH NITROGEN
}

\begin{abstract}
It is necessary to evaluate the soil physical and chemical attributes in studies that explore grazing systems intensively. In this work the variation in physical and chemical attributes of an Alfissol cultivated with Panicum maximum Jacq. cv. IPR-86 Milênio under grazing were evaluated from October 2001 to May 2002, in the fifth year of consecutive $N$ application at rates of $0,150,300$, and $450 \mathrm{~kg} \mathrm{ha}^{-1}$. After five successive applications of $450 \mathrm{~kg} \mathrm{ha}^{-1} \mathrm{~N}$, the OM content increased $5 \mathrm{~g} \mathrm{dm}^{-3}$, which resulted in CEC increase. From October 2001 to May 2002 the $\mathrm{pH}$ and basis saturation degree decreased with the increasing $N$ rates. The range in soil density with $N$ fertilization was small; the micropore percentage increased and the macropore percentage decreased in the $0-5 \mathrm{~cm}$ layer with increasing $N$ rates, but the total porosity remained constant; and the soil penetration resistance at $90 \mathrm{~g} \mathrm{ha}^{-1}$ of water was not affected by $\mathrm{N}$ rates and was not restrictive to plant growth.
\end{abstract}

Index terms: soil density, soil fertility, soil penetration resistance, soil porosity.

\section{INTRODUÇÃO}

Estudos que incluem a avaliação de novos cultivares de gramínea forrageira são necessários para obtenção de plantas com alta capacidade de produção e qualidade. O cultivar IPR-86 Milênio foi um dos mais promissores entre 25 acessos de Panicum maximum Jacq. avaliados pelo Instituto Agronômico do Paraná (IAPAR) em convênio com a Embrapa Gado de Corte, na região noroeste do Paraná (Lugão \& Abrahão, 1995).

A adubação nitrogenada é a principal responsável pelo aumento de produção das plantas forrageiras (Corsi \& Nussio, 1993). A intensificação do sistema de pastejo, por meio da adubação nitrogenada, promove o incremento do teor de matéria orgânica (MO) dos solos, que contribui para aumento da capacidade de retenção de água, da CTC (Corsi \& Nussio, 1993) e da estabilidade dos agregados (Silva \& Mielniczuk, 1997). A CTC representa o potencial para armazenamento de cátions do solo, enquanto a estabilidade dos agregados auxilia na melhoria da estrutura do solo, reduzindo o risco de compactação (Wheeler et al., 2002). Por outro lado, a adição de adubos nitrogenados, que contêm amônio, contribui para a acidificação do solo (Whitehead, 1990).

Em condições de pastejo, grande parte dos nutrientes é reciclada no sistema devido à morte de partes da planta, a perdas por pastejo e à incorporação de fezes e urina no solo. No entanto, a distribuição das dejeções é desuniforme na pastagem e varia em função do sistema de manejo adotado, da lotação e da movimentação de saleiros e cochos dentro do piquete (Braz et al., 2002).

A maior lotação animal nas pastagens promove melhor distribuição das dejeções, mas, se a lotação for excessiva, pode ocorrer alteração de atributos físicos do solo na camada superficial $(0-10 \mathrm{~cm})$ (Bertol et al., 2000), o que compromete o crescimento de raízes e de plantas (Harrison et al., 1994; Sarmento et al., 2008). Contudo, o período de descanso da pastagem apresenta correlação negativa com a densidade do solo (Silva et al., 2002), favorecendo a descompactação deste.

A cobertura do solo com restos vegetais amortece 0 impacto do pisoteio animal e reduz a perda de água por evaporação, evitando, assim, os ciclos de umedecimento e secamento, que, por sua vez, favorecem a compactação do solo (Mello, 2002; Silva et al., 2002).

A avaliação dos atributos químicos e físicos do solo se faz necessária em áreas que exploram intensivamente os sistemas de pastejo. O objetivo deste trabalho foi determinar os efeitos da adubação nitrogenada nos atributos físicos e químicos de um Argissolo Vermelho-Amarelo distrófico de textura arenosa cultivado com a espécie Panicum maximum Jacq. cv. IPR-86 Milênio, sob pastejo.

\section{MATERIAL E MÉTODOS}

O experimento foi realizado no IAPAR, em Paranavaí (PR) - nas coordenadas de $23^{\circ} 00^{\prime} 4^{\prime \prime} \mathrm{S}$, $42^{\circ} 02^{\prime} 06^{\prime \prime}$ W e altitude de $480 \mathrm{~m}$ - e implantado em Argissolo Vermelho-Amarelo distrófico de textura arenosa, com $890 \mathrm{~g} \mathrm{~kg}^{-1}$ de areia, 100 de argila e 10 de silte. Os dados de precipitação pluvial e temperatura média, relativos ao período de avaliação, estão apresentados na figura 1.

O capim-milênio foi semeado em outubro de 1995. As doses de $\mathrm{N}\left(0,150,300\right.$ e $450 \mathrm{~kg} \mathrm{ha}^{-1} \mathrm{ano}^{-1}$, 


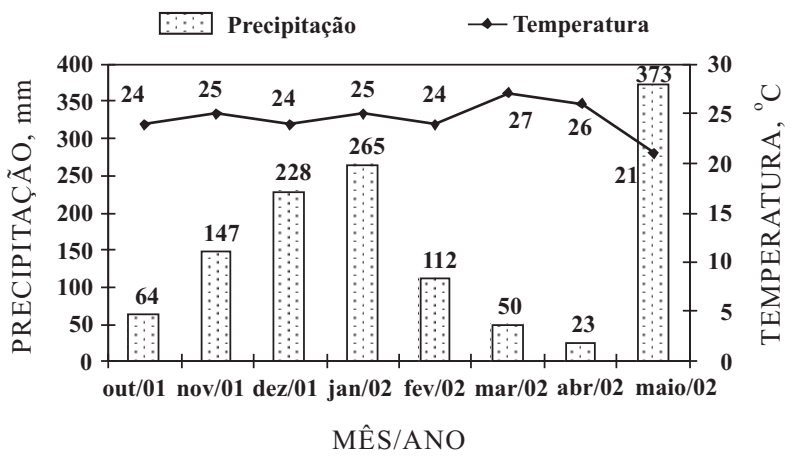

Figura 1. Precipitação pluvial e temperatura média registradas na Estação Agroclimática do IAPARParanavaí-PR, entre outubro de 2001 e maio de 2002.

parceladas em três doses iguais durante o período chuvoso) começaram a ser aplicadas na área experimental em outubro de 1997 e foram repetidas, ano a ano, até 2002. As quantidades de calcário e de fertilizantes aplicadas na área experimental, de 1997 a 2002 , estão no quadro 1 . Os resultados apresentados referem-se ao período de outubro/2001 a maio/2002. Durante o período experimental, as adubações com 150,300 e $450 \mathrm{~kg} \mathrm{ha}^{-1}$ de $\mathrm{N}$, na forma de nitrato de amônio, foram parceladas em três doses iguais durante os meses de outubro/ novembro de 2001, dezembro/janeiro de 2001/2002 e janeiro/fevereiro de 2002, e o adubo foi distribuído manualmente, um dia após a saída dos animais de cada piquete. Não se aplicou calcário, $\mathrm{P}$ e K na área durante o período experimental, e os resultados de análise química do solo amostrado em junho de 2001 podem ser observados no quadro 2 .

O método de pastejo utilizado foi o de lotação rotacionada, com período de ocupação de cinco dias e 35 dias de descanso, correspondendo a um ciclo de pastejo de 40 dias. Assim, foram necessários oito piquetes para cada tratamento de dose de $\mathrm{N}$ para que o ciclo de pastejo pudesse ser completado. Contudo, as avaliações foram feitas em quatro piquetes de cada tratamento. Foram realizados quatro ciclos de pastejo entre 20/10/2001 e 8/5/2002.

As unidades experimentais que receberam as doses de 0 e $150 \mathrm{~kg} \mathrm{ha}^{-1}$ de $\mathrm{N}$ apresentavam área de $1.687,3 \mathrm{~m}^{2}$ cada ( $36 \times 46,87 \mathrm{~m}$ ), enquanto as que receberam as doses de 300 e $450 \mathrm{~kg} \mathrm{ha}^{-1}$ de N tinham $838,8 \mathrm{~m}^{2}$ cada $(36 \times 23,3 \mathrm{~m})$. A dimensão das áreas dos piquetes dos tratamentos sem aplicação de $\mathrm{N}$ e com dose de $150 \mathrm{~kg} \mathrm{ha}^{-1}$ de $\mathrm{N}$ foi o dobro das áreas dos tratamentos de 300 e $450 \mathrm{~kg} \mathrm{ha}^{-1}$ de $\mathrm{N}$, devido à menor produção de forragem que os dois primeiros tratamentos proporcionavam e à conseqüente necessidade de maior área para que fosse possível manter uma quantidade mínima de forragem no piquete que comportasse pelo menos três bovinos, para avaliação de ganho de peso do animal.
Os bovinos eram colocados e removidos dos pastos experimentais para ajustar o número de animais à oferta de forragem disponível, segundo o método descrito por Mott \& Lucas (1952). Considerou-se o consumo de 70 \% de matéria seca de lâminas verdes, em relação à produção de forragem para cada dose de $\mathrm{N}$, e também a oferta diária desta de $11 \mathrm{~kg}$ por $450 \mathrm{~kg}$ de peso corporal. O manejo foi realizado visando deixar um resíduo de 20 a $25 \%$ de lâminas verdes em relação à produção, em cada piquete, com cada dose de N. Os animais utilizados foram novilhos inteiros cruzados (Nelore x Marchigiana, Nelore x Simental e Nelore x Red Angus).

As amostragens de solo para as análises químicas foram realizadas no início (outubro de 2001) e no fim do período experimental (maio de 2002). As avaliações abrangeram a "época das águas", em razão de $80 \%$, ou mais, da produção de forragem ocorrer nesse período na região noroeste do Estado do Paraná, em decorrência das maiores temperaturas e precipitação pluvial. Contudo, a precipitação pluvial registrada no mês de maio (Figura 1) foi maior que a esperada e, portanto, atípica. Utilizou-se um trado tipo sonda

Quadro 1. Adubações e calagens da área experimental feitas entre os anos de 1997 e 2002

\begin{tabular}{|c|c|c|c|c|}
\hline Ano & $\mathbf{N}^{(1)}$ & $\mathrm{P}_{2} \mathrm{O}_{5}{ }^{(2)}$ & $\mathbf{K}_{2} \mathbf{O}^{(3)}$ & Calcário $^{(4)}$ \\
\hline & 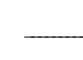 & $-\mathrm{kg} \mathrm{ha}^{-1}$ & - & $\mathrm{t} \mathrm{ha}^{-1}$ \\
\hline \multirow[t]{4}{*}{$97 / 98$} & 0 & - & 60 & - \\
\hline & 150 & - & 105 & - \\
\hline & 300 & - & 210 & - \\
\hline & 450 & - & 315 & - \\
\hline \multirow[t]{4}{*}{$98 / 99$} & 0 & 65 & 60 & 1,0 \\
\hline & 150 & 65 & 105 & 1,2 \\
\hline & 300 & 65 & 210 & 1,5 \\
\hline & 450 & 65 & 315 & 1,7 \\
\hline \multirow[t]{4}{*}{$99 / 00$} & 0 & - & 60 & - \\
\hline & 150 & - & 105 & - \\
\hline & 300 & - & 210 & - \\
\hline & 450 & - & 315 & - \\
\hline \multirow[t]{4}{*}{$00 / 01$} & 0 & 60 & 60 & 1,0 \\
\hline & 150 & 60 & 105 & 1,0 \\
\hline & 300 & 60 & 210 & 1,0 \\
\hline & 450 & 60 & 315 & 1,0 \\
\hline \multirow[t]{4}{*}{$01 / 02$} & 0 & - & - & - \\
\hline & 150 & - & - & - \\
\hline & 300 & - & - & - \\
\hline & 450 & - & - & - \\
\hline
\end{tabular}

(1) Nitrocálcio em 97/98, 98/99 e 99/00 e nitrato de amônio em 00/01 e 01/02 ${ }^{(2)}$ Superfosfato simples. ${ }^{(3)}$ Cloreto de potássio. (4) PRNT do calcário dolomítico $=89 \%$. 
Quadro 2. Atributos químicos do solo na profundidade de 0 a $20 \mathrm{~cm}$, em junho de 2001

\begin{tabular}{|c|c|c|c|c|c|c|c|c|c|}
\hline Dose de N & $\mathbf{P}^{(1)}$ & $\mathrm{pH} \mathrm{CaCl} 2$ & $\mathbf{H}+\mathbf{A l}$ & $\mathrm{Ca}$ & Mg & $\mathbf{K}$ & $\mathbf{S B}^{(2)}$ & CTC & V \\
\hline $\mathrm{kg} \mathrm{ha}{ }^{-1}$ & $\mathrm{mg} \mathrm{dm}{ }^{-3}$ & & $\ldots$ & 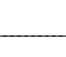 & $-\mathrm{m}$ & $n^{-3}$ & & - & $\%$ \\
\hline 0 & 7 & 6,3 & 17 & 23 & 11 & 2,7 & 37 & 54 & 68 \\
\hline 150 & 7 & 6,2 & 17 & 20 & 9 & 2,1 & 31 & 48 & 65 \\
\hline 300 & 7 & 6,4 & 16 & 19 & 9 & 3,5 & 32 & 48 & 66 \\
\hline 450 & 9 & 6,3 & 16 & 19 & 9 & 2,9 & 31 & 47 & 66 \\
\hline
\end{tabular}

${ }^{(1)}$ Extraído por Mehlich-1. ${ }^{(2)}$ Soma de bases.

graduada para realização das amostragens do solo. Foram retiradas 25 subamostras de solo por piquete, de maneira aleatória, para constituir a amostra; as profundidades do solo avaliadas foram de 0-10, 10-20 e $20-40 \mathrm{~cm}$. As análises químicas foram feitas segundo os métodos descritos por Raij et al. (1987).

Para avaliação da densidade do solo e das percentagens de poros totais, de macroporos e de microporos, foram coletadas quatro amostras de solo em cada piquete, em duas profundidades $(0-5$ e $5-10 \mathrm{~cm})$. Foram utilizados anéis volumétricos de $50,0 \mathrm{~mm}$ de altura e 50,8 mm de diâmetro. As amostragens de solo foram efetuadas oito dias após a saída dos animais do piquete, nos meses de fevereiro e março de 2002, e os atributos foram determinados conforme método descrito pela Embrapa (1997).

A penetrabilidade ou resistência do solo à penetração foi medida após cinco dias de chuvas consecutivas (precipitação de $123,7 \mathrm{~mm}$ ), nos dias 16 , 17, 18 e 19 de janeiro de 2002, nas profundidades de 0-10, 10-20 e 20-40 cm, por meio do penetrógrafo, em 20 pontos por piquete. As leituras foram feitas de maneira aleatória dentro do piquete, evitando-se os locais próximos às cercas e à porteira. Foram também realizadas quatro amostragens de solo por piquete em três profundidades $(0-10,10-20$ e 20-40 cm), por meio de um trado tipo sonda graduada, para determinação da umidade gravimétrica pelo método descrito pela Embrapa (1997), que nesse momento foi de $90 \mathrm{~g} \mathrm{~kg}^{-1}$.

Após uma estiagem de 10 dias, tentou-se medir a resistência do solo à penetração, no dia 12 de fevereiro de 2002. As leituras foram feitas em apenas uma repetição dos tratamentos, porque não ocorreu a penetração do cone do equipamento na camada superficial do solo na maioria das medições realizadas, devido ao baixo teor de água no solo (média de $20 \mathrm{~g} \mathrm{~kg}^{-1}$ ) e à alta resistência. Em razão disso, não foi realizada análise estatística das leituras efetuadas nesse período.

$\mathrm{O}$ delineamento estatístico foi o inteiramente casualizado, com quatro repetições, em esquema de parcelas subdivididas com medidas repetidas no espaço, para os atributos físicos do solo. Por sua vez, os atributos químicos do solo foram analisados em esquema de parcelas sub-subdivididas, com medidas repetidas no tempo e no espaço. As doses de $\mathrm{N}$ foram estudadas nas parcelas principais; as profundidades para avaliação dos atributos físicos e químicos do solo, nas subparcelas; e as épocas de amostragem para avaliação da fertilidade do solo, nas subsubparcelas.

Os resultados foram analisados por meio do programa estatístico SAS (Statistical Analysis System) (SAS, 1999), versão 8.2 para Windows, adotando-se o PROC MIXED. O efeito das doses de $\mathrm{N}$ nas variáveisresposta foi estudado por meio de análises de regressão. Para as profundidades de coleta, os resultados foram analisados pelo teste de Tukey, enquanto a comparação entre as épocas de amostragem do solo foi feita pelo teste F. O nível de significância adotado foi de $5 \%$.

\section{RESULTADOS E DISCUSSÃO}

\section{Atributos químicos do solo}

Por meio da análise de variância, detectou-se significância para interação entre as profundidades e as doses de $\mathrm{N}$ para $\mathrm{pH}$, matéria orgânica, $\mathrm{K}, \mathrm{Mg}^{2+} \mathrm{e}$ saturação por bases (Quadro 3). Entre as profundidades e as épocas de amostragem do solo, verificou-se interação significativa para $\mathrm{pH}, \mathrm{P}, \mathrm{K}, \mathrm{Ca}^{2+}, \mathrm{Mg}^{2+}, \mathrm{CTC}$ e saturação por bases (Quadro 4), e a interação entre doses de $\mathrm{N}$ e épocas de amostragem foi significativa somente para matéria orgânica, CTC e teor de $\mathrm{Mg}^{2+}$ no solo (Quadro 5).

O maior teor de MO na camada mais superficial do solo, comparado ao das demais camadas (Quadro 3), se deve à maior concentração de raízes nessa camada e à deposição superficial dos excrementos dos animais e do resíduo da parte aérea do capim, que senesceu e morreu antes de ser consumida. Durante o período das avaliações dos atributos químicos, os valores médios de densidade de raízes foram de 790, 370 e $190 \mathrm{mg} \mathrm{dm}^{-3}$ nas camadas de $0-10,10-20$ e $20-40 \mathrm{~cm}$ de profundidade, respectivamente (Sarmento et al., 2008). 
Quadro 3. Atributos químicos do solo em função das profundidades de amostragem e das doses de nitrogênio (médias para as épocas de amostragem)

\begin{tabular}{|c|c|c|c|c|c|c|c|}
\hline \multirow{2}{*}{ Profundidade } & \multicolumn{5}{|c|}{ Dose de N $\left(\mathrm{kg} \mathrm{ha}^{-1}\right)$} & \multirow{2}{*}{ Equação } & \multirow{2}{*}{$\mathbf{R}^{2}$} \\
\hline & 0 & 150 & 300 & 450 & Média & & \\
\hline $\mathrm{cm}$ & \multicolumn{5}{|c|}{$\mathrm{pH}\left(\mathrm{CaCl}_{2}\right)$} & & \\
\hline $0-10$ & $5,8 \mathrm{a}^{(1)}$ & $5,9 \mathrm{a}$ & $5,9 \mathrm{a}$ & $5,7 \mathrm{a}$ & 5,8 & $\hat{y}=5,80+0,0013 x-0,000003 x^{2}$ & $0,98^{*}$ \\
\hline $10-20$ & $5,6 \mathrm{~b}$ & $5,5 \mathrm{~b}$ & $5,2 \mathrm{~b}$ & $5,0 \mathrm{~b}$ & 5,3 & $\hat{\mathrm{y}}=5,64-0,00014 \mathrm{x}$ & 0,97 * \\
\hline $20-40$ & $5,2 \mathrm{c}$ & $5,0 \mathrm{c}$ & $4,9 \mathrm{c}$ & $4,7 \mathrm{c}$ & 5,0 & $\hat{y}=5,19-0,0011 x$ & $0,98^{*}$ \\
\hline \multirow[t]{2}{*}{ Média } & 5,5 & 5,5 & 5,3 & 5,1 & & - & - \\
\hline & \multicolumn{5}{|c|}{$\mathrm{MO}\left(\mathrm{g} \mathrm{dm}^{-3}\right)$} & & \\
\hline $0-10$ & $15 \mathrm{a}$ & $17 \mathrm{a}$ & $21 \mathrm{a}$ & $20 \mathrm{a}$ & 18 & $\hat{y}=14,65+0,0277 x-0,00003 x^{2}$ & $0,89^{*}$ \\
\hline $10-20$ & $11 \mathrm{~b}$ & $11 \mathrm{~b}$ & $14 \mathrm{~b}$ & $14 \mathrm{~b}$ & 13 & $\hat{y}=10,7+0,008 x$ & $0,80^{*}$ \\
\hline $20-40$ & $9 \mathrm{c}$ & $8 \mathrm{c}$ & $9 \mathrm{c}$ & $9 \mathrm{c}$ & 9 & $\mathrm{~ns}$ & - \\
\hline \multirow[t]{2}{*}{ Média } & 12 & 12 & 15 & 14 & & - & - \\
\hline & \multicolumn{5}{|c|}{$\mathrm{P}\left(\mathrm{mg} \mathrm{dm}^{-3}\right)$} & & \\
\hline $0-10$ & 14 & 13 & 13 & 12 & 13 & - & - \\
\hline $10-20$ & 4 & 4 & 5 & 5 & 5 & - & - \\
\hline $20-40$ & 3 & 3 & 3 & 3 & 3 & - & - \\
\hline \multirow[t]{2}{*}{ Média } & 7 & 7 & 7 & 7 & & ns & - \\
\hline & \multicolumn{5}{|c|}{$\mathrm{K}\left(\mathrm{mmol}_{\mathrm{c}} \mathrm{dm}^{-3}\right)$} & & \\
\hline $0-10$ & $2,1 \mathrm{a}$ & $2,5 \mathrm{a}$ & $4,0 \mathrm{a}$ & $4,2 \mathrm{a}$ & 3,2 & $\hat{y}=2,03+0,0052 x$ & $0,91^{*}$ \\
\hline $10-20$ & $2,0 \mathrm{a}$ & $1,8 \mathrm{ab}$ & $2,8 \mathrm{~b}$ & $3,0 \mathrm{~b}$ & 2,4 & $\hat{y}=1,80+0,0027 x$ & $0,77^{*}$ \\
\hline $20-40$ & $1,9 \mathrm{a}$ & $1,6 \mathrm{~b}$ & $1,7 \mathrm{c}$ & $1,9 \mathrm{c}$ & 1,8 & $\mathrm{~ns}$ & - \\
\hline \multirow[t]{2}{*}{ Média } & 2,0 & 2,0 & 2,8 & 3,0 & & - & - \\
\hline & \multicolumn{5}{|c|}{$\mathrm{Ca}^{2+}\left(\mathrm{mmol}_{\mathrm{c}} \mathrm{dm}^{-3}\right)$} & & \\
\hline $0-10$ & 20 & 21 & 21 & 21 & 21 & - & - \\
\hline $10-20$ & 15 & 15 & 14 & 13 & 14 & - & - \\
\hline $20-40$ & 12 & 11 & 12 & 10 & 11 & - & - \\
\hline \multirow[t]{2}{*}{ Média } & 16 & 16 & 16 & 15 & & $\mathrm{~ns}$ & - \\
\hline & \multicolumn{5}{|c|}{$\mathrm{Mg}^{2+}\left(\mathrm{mmol}_{\mathrm{c}} \mathrm{dm}^{-3}\right)$} & & \\
\hline $0-10$ & $10 \mathrm{a}$ & $13 \mathrm{a}$ & $12 \mathrm{a}$ & $14 \mathrm{a}$ & 16 & $\hat{y}=10,6+0,0073 x$ & $0,69^{*}$ \\
\hline $10-20$ & $7 \mathrm{~b}$ & $7 \mathrm{~b}$ & $8 b$ & $8 b$ & 8 & $\mathrm{~ns}$ & - \\
\hline $20-40$ & $6 \mathrm{~b}$ & $5 \mathrm{c}$ & $7 \mathrm{~b}$ & $5 \mathrm{c}$ & 6 & $\mathrm{~ns}$ & - \\
\hline \multirow[t]{2}{*}{ Média } & 8 & 8 & 9 & 9 & & - & - \\
\hline & \multicolumn{5}{|c|}{ CTC $\left(\mathrm{mmol}_{\mathrm{c}} \mathrm{dm}^{-3}\right)$} & & \\
\hline $0-10$ & 44 & 49 & 52 & 52 & $49 \mathrm{a}$ & - & - \\
\hline $10-20$ & 37 & 37 & 41 & 42 & $39 \mathrm{~b}$ & - & - \\
\hline $20-40$ & 36 & 35 & 38 & 38 & $37 \mathrm{~b}$ & - & - \\
\hline \multirow[t]{2}{*}{ Média } & 39 & 40 & 44 & 44 & & $\hat{y}=38,9+0,0127 x$ & $0,87^{*}$ \\
\hline & & & V (\%) & & & & \\
\hline $0-10$ & $73 \mathrm{a}$ & $76 a$ & $75 \mathrm{a}$ & $74 \mathrm{a}$ & 75 & $\mathrm{~ns}$ & - \\
\hline $10-20$ & $64 \mathrm{~b}$ & $64 \mathrm{~b}$ & $61 \mathrm{~b}$ & $56 \mathrm{~b}$ & 61 & $\hat{y}=65,3-0,018 x$ & $0,85^{*}$ \\
\hline $20-40$ & $57 \mathrm{c}$ & $51 \mathrm{c}$ & $54 \mathrm{c}$ & $44 \mathrm{c}$ & 52 & $\hat{y}=56,9-0,024 x$ & $0,70^{*}$ \\
\hline Média & 65 & 64 & 63 & 58 & & - & - \\
\hline
\end{tabular}

(1) Para uma mesma variável, médias seguidas de mesma letra, em cada coluna, não diferem entre si pelo teste de Tukey a $5 \%$. Coeficientes de variação obtidos para $\mathrm{pH}, \mathrm{MO}, \mathrm{P}, \mathrm{K}, \mathrm{Ca}^{2+}, \mathrm{Mg}^{2+}$, CTC e V: 3, 9, 22, 19, 14, 14, 7 e $8 \%$, respectivamente. *: Significativo a $5 \%$ pelo teste $\mathrm{F}$ e ns: não-significativo. 
Quadro 4. Atributos químicos do solo em função das épocas e das profundidades de amostragem (médias para as doses de nitrogênio)

\begin{tabular}{|c|c|c|c|c|c|c|}
\hline \multirow{2}{*}{ Profundidade } & \multicolumn{2}{|c|}{ Amostragem } & \multirow{2}{*}{ Média } & \multicolumn{2}{|c|}{ Amostragem } & \multirow{2}{*}{ Média } \\
\hline & $10 / 2001^{(1)}$ & $5 / 2002^{(2)}$ & & $10 / 2001$ & $5 / 2002$ & \\
\hline $\mathrm{cm}$ & \multicolumn{3}{|c|}{$\mathrm{pH}\left(\mathrm{CaCl}_{2}\right)$} & \multicolumn{3}{|c|}{$\operatorname{MO}\left(\mathrm{g} \mathrm{dm}^{-3}\right)$} \\
\hline $0-10$ & $6,1 \mathrm{aA}^{(3)}$ & $5,6 \mathrm{bA}$ & 5,9 & 18 & 18 & 18 \\
\hline $10-20$ & $5,4 \mathrm{aB}$ & $5,3 \mathrm{aB}$ & 5,4 & 13 & 12 & 13 \\
\hline $20-40$ & $4,8 \mathrm{bC}$ & $5,0 \mathrm{aC}$ & 4,9 & 8 & 8 & 8 \\
\hline \multirow[t]{2}{*}{ Média } & 5,4 & 5,3 & & $13 \mathrm{a}$ & $13^{\mathrm{a}}$ & \\
\hline & \multicolumn{3}{|c|}{$\mathrm{P}\left(\mathrm{mg} \mathrm{dm} \mathrm{m}^{-3}\right)$} & \multicolumn{3}{|c|}{$\mathrm{K}\left(\mathrm{mmol}_{\mathrm{c}} \mathrm{dm}^{-3}\right)$} \\
\hline $0-10$ & $16 \mathrm{aA}$ & $10 \mathrm{bA}$ & 13 & $3,0 \mathrm{bA}$ & $3,5 \mathrm{aA}$ & 3,3 \\
\hline $10-20$ & $5 \mathrm{aB}$ & $4 \mathrm{bB}$ & 5 & $2,4 \mathrm{aB}$ & $2,3 \mathrm{aB}$ & 2,4 \\
\hline $20-40$ & $3 \mathrm{aC}$ & $3 \mathrm{aC}$ & 3 & $1,6 \mathrm{bC}$ & $2,0 \mathrm{aB}$ & 1,8 \\
\hline \multirow[t]{2}{*}{ Média } & 8 & 6 & & 2,3 & 2,6 & \\
\hline & \multicolumn{3}{|c|}{$\mathrm{Ca}^{2+}\left(\mathrm{mmol}_{\mathrm{c}} \mathrm{dm}^{-3}\right)$} & \multicolumn{3}{|c|}{$\mathrm{Mg}^{2+}\left(\mathrm{mmol}_{\mathrm{c}} \mathrm{dm}^{-3}\right)$} \\
\hline $0-10$ & $22 \mathrm{aA}$ & $20 \mathrm{aA}$ & 21 & $14 \mathrm{aA}$ & $11 \mathrm{bA}$ & 13 \\
\hline $10-20$ & $13 \mathrm{aB}$ & $15 \mathrm{aB}$ & 14 & $7 \mathrm{aB}$ & $8 \mathrm{aB}$ & 8 \\
\hline $20-40$ & $10 \mathrm{bC}$ & $13 \mathrm{aB}$ & 12 & $6 \mathrm{aC}$ & $6 \mathrm{aC}$ & 6 \\
\hline \multirow[t]{2}{*}{ Média } & 15 & 16 & & 9 & 8 & \\
\hline & \multicolumn{3}{|c|}{$\mathrm{CTC}\left(\mathrm{mmol}_{\mathrm{c}} \mathrm{dm}^{-3}\right)$} & \multicolumn{3}{|c|}{ V $(\%)$} \\
\hline $0-10$ & $51 \mathrm{aA}$ & $47 \mathrm{bA}$ & 49 & $77 \mathrm{aA}$ & $72 \mathrm{bA}$ & 75 \\
\hline $10-20$ & $37 \mathrm{bB}$ & $41 \mathrm{aB}$ & 39 & $60 \mathrm{aB}$ & $62 \mathrm{aB}$ & 61 \\
\hline $20-40$ & $35 \mathrm{bB}$ & $38 \mathrm{aB}$ & 37 & $49 \mathrm{aC}$ & $54 \mathrm{aC}$ & 52 \\
\hline Média & 41 & 42 & & 62 & 63 & \\
\hline
\end{tabular}

${ }^{(1)}$ Amostragem efetuada no início do período experimental. ${ }^{(2)}$ Amostragem realizada no fim do período experimental. ${ }^{(3)}$ Para uma mesma variável, médias seguidas de mesma letra minúscula na linha não diferem entre si pelo teste $\mathrm{F}$ a $5 \%$, e médias seguidas de mesma letra maiúscula na coluna não diferem entre si pelo teste de Tukey a $5 \%$. Coeficientes de variação obtidos para $\mathrm{pH}$, MO, P, K, $\mathrm{Ca}^{2+}, \mathrm{Mg}^{2+}$, CTC e V: $3,9,22,19,14,14,7$ e $8 \%$, respectivamente.

Houve aumento do teor de MO em função da adubação nitrogenada nas profundidades de $0-10$ e $10-20 \mathrm{~cm}$ (Quadro 3). Na primeira condição o efeito foi quadrático e, na segunda, linear. Isso está relacionado ao aumento da produção da forrageira que levou a maior quantidade de material senescente, ao aumento de dejeções dos animais em razão do seu maior número para ajustar a lotação com a produção vegetal e às perdas de forragem devido ao pisoteio. Assim, quanto maior a dose de N, maior é a produção da forragem, a lotação das pastagens e a quantidade de dejeções dos animais. Neste experimento, as médias de massa de forragem no pré-pastejo foram de $705,4319,6.135$ e $5.968 \mathrm{~kg} \mathrm{ha}^{-1}$ de MS para as doses de $0,150,300$ e $450 \mathrm{~kg} \mathrm{ha}^{-1}$ de $\mathrm{N}$, respectivamente (Sarmento et al., 2005). A lotação das pastagens foi em torno de 3, 6, 9 e $10 \mathrm{UA} \mathrm{ha}^{-1}$, entre outubro/1998 e março/1999 (Lugão, 2001), e de 2, 6, 9 e 10 UA ha $^{-1}$, entre outubro/2001 e março/2002, para as doses de 0 ,
150,300 e $450 \mathrm{~kg} \mathrm{ha}^{-1}$ de N, respectivamente. Durante o inverno, a lotação das pastagens foi de 15 a $20 \%$ daquela do período mencionado anteriormente.

No experimento pode ter ocorrido aumento da perda de partes das plantas durante o pastejo por causa da maior altura da gramínea nas maiores doses de $\mathrm{N}$, contribuindo, portanto, com o conseqüente aumento do teor de MO do solo. Hillesheim \& Corsi (1990) relataram que há correlação positiva da altura das plantas com as perdas de forragem pelo pastejo.

A variação de $5 \mathrm{~g} \mathrm{dm}^{-3} \mathrm{de}$ MO na profundidade de 0-10 cm, comparando-se os tratamentos com as doses de 0 e $450 \mathrm{~kg} \mathrm{ha}^{-1}$ de N (Quadro 3), é resultado da reaplicação do $\mathrm{N}$ ao longo de cinco anos e da conseqüente deposição adicional sobre o solo das fezes dos animais e da parte aérea da planta que não foi consumida, além do aumento da quantidade de raízes produzidas (Quadros 4 e 5). Neste último, constata- 
Quadro 5. Atributos químicos do solo em função das épocas de amostragem e das doses de nitrogênio (médias para as profundidades de amostragem)

\begin{tabular}{|c|c|c|c|c|c|c|c|}
\hline \multirow{2}{*}{ Amostragem } & \multicolumn{5}{|c|}{ Dose de N $\left(\mathrm{kg} \mathrm{ha}^{-1}\right)$} & \multirow{2}{*}{ Equação } & \multirow{2}{*}{$\mathbf{R}^{2}$} \\
\hline & 0 & 150 & 300 & 450 & Média & & \\
\hline \multicolumn{8}{|c|}{$\mathrm{pH}\left(\mathrm{CaCl}_{2}\right)$} \\
\hline $10 / 2001^{(1)}$ & 5,6 & 5,5 & 5,4 & 5,3 & 5,5 & - & - \\
\hline $5 / 2002^{(2)}$ & 5,4 & 5,4 & 5,3 & 5,0 & 5,4 & - & - \\
\hline Média & 5,5 & 5,5 & 5,4 & 5,2 & & $\mathrm{~ns}$ & - \\
\hline \multicolumn{8}{|c|}{$\operatorname{MO}\left(\mathrm{g} \mathrm{dm}^{-3}\right)$} \\
\hline $10 / 2001$ & 12 & 12 & 15 & 15 & 14 & $\hat{y}=11,7+0,008 x$ & $0,80^{*}$ \\
\hline $5 / 2002$ & 12 & 12 & 14 & 14 & 13 & $\hat{y}=11,8+0,005 x$ & $0,80^{*}$ \\
\hline Média & 12 & 12 & 15 & 15 & & - & - \\
\hline \multicolumn{8}{|c|}{$\mathrm{P}\left(\mathrm{mg} \mathrm{dm}^{-3}\right)$} \\
\hline $10 / 2001$ & 8 & 7 & 8 & 8 & 8 & - & - \\
\hline $5 / 2002$ & 5 & 6 & 6 & 7 & 6 & - & - \\
\hline Média & 7 & 7 & 7 & 8 & & $\mathrm{~ns}$ & - \\
\hline \multicolumn{8}{|c|}{$\mathrm{K}\left(\mathrm{mmol}_{\mathrm{c}} \mathrm{dm}^{-3}\right)$} \\
\hline $10 / 2001$ & 1,8 & 1,9 & 2,8 & 2,9 & 2,4 & - & - \\
\hline $5 / 2002$ & 2,2 & 2,0 & 2,9 & 3,3 & 2,6 & - & - \\
\hline Média & 2,0 & 2,0 & 2,9 & 3,1 & & $\mathrm{~ns}$ & - \\
\hline \multicolumn{8}{|c|}{$\mathrm{Ca}^{2+}\left(\mathrm{mmolc}_{\mathrm{cm}}{ }^{-3}\right)$} \\
\hline $10 / 2001$ & 15 & 15 & 16 & 15 & 15 & - & - \\
\hline $5 / 2002$ & 16 & 17 & 16 & 14 & 16 & - & - \\
\hline Média & 16 & 16 & 16 & 15 & & $\mathrm{~ns}$ & - \\
\hline \multicolumn{8}{|c|}{$\mathrm{Mg}^{2+}\left(\mathrm{mmol}_{\mathrm{c}} \mathrm{dm}^{-3}\right)$} \\
\hline $10 / 2001$ & $8 a^{(3)}$ & $8 \mathrm{a}$ & $10 \mathrm{a}$ & $10 \mathrm{a}$ & 9 & $\hat{y}=7,80+0,0053 x$ & $0,80^{*}$ \\
\hline $5 / 2002$ & $8 \mathrm{a}$ & $8 \mathrm{a}$ & $8 \mathrm{a}$ & $8 \mathrm{~b}$ & 8 & $\mathrm{~ns}$ & - \\
\hline Média & 8 & 8 & 9 & 9 & & - & - \\
\hline \multicolumn{8}{|c|}{$\mathrm{CTC}\left(\mathrm{mmolc} \mathrm{dm}^{-3}\right)$} \\
\hline $10 / 2001$ & 37 & 39 & 44 & 44 & 41 & $\hat{y}=37,1+0,017 x$ & $0,89^{*}$ \\
\hline $5 / 2002$ & 40 & 41 & 43 & 44 & 42 & $\hat{y}=39,9+0,009 x$ & $0,98^{*}$ \\
\hline Média & 39 & 40 & 44 & 44 & & - & - \\
\hline \multicolumn{8}{|c|}{ V (\%) } \\
\hline $10 / 2001$ & 64 & 62 & 63 & 60 & 62 & - & - \\
\hline $5 / 2002$ & 65 & 65 & 63 & 55 & 62 & - & - \\
\hline Média & 65 & 64 & 63 & 58 & & $\mathrm{~ns}$ & - \\
\hline
\end{tabular}

(1) Amostragem efetuada no início do período experimental. ${ }^{(2)}$ Amostragem realizada no final do período experimental. ${ }^{(3)}$ Para uma mesma variável, médias seguidas de mesma letra, em cada coluna, não diferem entre si pelo teste de Tukey a $5 \%$. Coeficientes de variação obtidos para $\mathrm{pH}, \mathrm{MO}, \mathrm{P}, \mathrm{K}, \mathrm{Ca}^{2+}, \mathrm{Mg}^{2+}$, CTC e V: $3,9,22,19,14,14,7$ e $8 \%$, respectivamente. *: Significativo a $5 \%$ pelo teste $\mathrm{F}$ e ns: não-significativo.

se aumento linear do teor de MO com a aplicação de $\mathrm{N}$ na amostragem de solo feita em outubro/2001, e esta reflete os efeitos das doses de $\mathrm{N}$ aplicadas em anos anteriores a 2001/2002. Observou-se aumento linear do teor de $\mathrm{MO}$ com as doses de $\mathrm{N}$ na amostragem feita em maio/2002 (Quadro 5 ), a qual reflete o efeito acumulado dos tratamentos, inclusive das doses de $\mathrm{N}$ aplicadas em 2001/2002. Como esperado, no período 
de outubro/2001 a maio/2002, não foi observada variação no teor de $\mathrm{MO}$ (Quadro 4), o que comprova que o aumento observado é resultado da reaplicação sucessiva dos tratamentos em anos anteriores.

Com a adubação nitrogenada, houve aumento linear da CTC do solo (Quadro 3) tanto na amostragem do solo feita no início como no final do período experimental (Quadro 5). Esses resultados são conseqüência do aumento do teor de MO do solo, principal fonte de cargas negativas, com a aplicação das doses de N (Quadros 3 e 5).

Houve diminuição nos valores de $\mathrm{V}$ e de $\mathrm{pH}$ do solo com o aumento da profundidade (Quadros 3 e 4). Nas profundidades de $10-20$ e de $20-40 \mathrm{~cm}$, os valores de $\mathrm{V}$ e de $\mathrm{pH}$ do solo apresentaram decréscimo linear em função das doses de $\mathrm{N}$, enquanto na camada de 0 $10 \mathrm{~cm}$ houve efeito quadrático para os valores de $\mathrm{pH}$ (Quadro 3). Detectou-se também decréscimo nos valores de $\mathrm{V}$ e de $\mathrm{pH}$ do solo no fim do período experimental, em relação ao início, na profundidade de 0-10 cm (Quadro 4). A diminuição da V - e conseqüente diminuição do valor de $\mathrm{pH}$ - no final do período experimental - deve-se à lixiviação das bases do solo e, ou, à sua absorção pelas plantas, associadas à decomposição dos resíduos vegetais no processo de mineralização e formação das substâncias húmicas pelos microrganismos (B̉ohnen, 2000) e à produção de $\mathrm{H}^{+}$decorrente da nitrificação do $\mathrm{N}-\mathrm{NH}_{4}{ }^{+}$proveniente da deposição de fezes e urina dos animais (Mapfumo et al., 2000) e dos fertilizantes que contêm ou produzem $\mathrm{N}_{-} \mathrm{NH}_{4}{ }^{+}$(Whitehead, 1990). Por outro lado, detectou-se aumento no valor de $\mathrm{pH}$ do solo ao final do período experimento na profundidade de $20-40 \mathrm{~cm}$ (Quadro 4).

Com o aumento da profundidade do solo houve decréscimo dos teores de MO, em todas as doses de N, e de K trocável nas doses de 150,300 e $450 \mathrm{~kg} \mathrm{ha}^{-1}$ de $\mathrm{N}$, além da diminuição na CTC, nos teores de $\mathrm{P}$ disponível, $\mathrm{K}, \mathrm{Ca}$ e Mg trocáveis, tanto no início como no final do período experimental (Quadros 3 e 4). Isso se deve ao fato de as arações e gradagens utilizadas no preparo do solo para semeadura do capim-milênio e das culturas que o antecederam, no período compreendido entre 1993 e 1995, não terem atingido grandes profundidades para incorporação do corretivo e dos adubos ao solo. Ademais, a manutenção da fertilidade do solo, da implantação do capim até fevereiro de 2001, foi feita por adubações (duas com $P$ e seis com K) e correções da acidez (duas calagens) em cobertura e sem incorporação.

Por intermédio do desdobramento da interação de doses de $\mathrm{N}$ dentro de cada profundidade de amostragem do solo, constatou-se que nos tratamentos que receberam N, nas profundidades de $0-10$ e $10-20 \mathrm{~cm}$ (Quadro 3), o teor de $\mathrm{K}$ trocável no solo foi maior. Verificou-se, também, maior teor desse nutriente no final do experimento, em comparação ao início, nas camadas de 0-10 e 20-40 cm (Quadro 4). Esses fatos estão relacionados à reciclagem do $\mathrm{K}$ ingerido pelos animais, que retorna à pastagem como fezes e urina (Braz et al., 2002). Por outro lado, as aplicações de $\mathrm{KCl}$ em anos anteriores (de outubro de 1997 a fevereiro de 2001), em quantidades proporcionais às de $\mathrm{N}$ adicionadas $\left(70 \%\right.$ de $\mathrm{K}_{2} \mathrm{O}$ em relação à quantidade de $\mathrm{N}$, sendo $60 \mathrm{~kg} \mathrm{ha}^{-1}$ de $\mathrm{K}_{2} \mathrm{O}$ aplicados nas unidades experimentais mesmo quando não se empregou o $\mathrm{N})$, contribuíram para aumento do teor de K trocável do solo. Além disso, o $\mathrm{NH}_{4} \mathrm{NO}_{3}$, que possuía $3 \%$ de $\mathrm{K}_{2} \mathrm{O}$ em sua composição, contribuiu para elevação do teor de $\mathrm{K}$ no solo em, aproximadamente, 14, $28 \mathrm{e}$ $42 \mathrm{~kg} \mathrm{ha}^{-1}$ de $\mathrm{K}_{2} \mathrm{O}$ com a aplicação de 150,300 e $450 \mathrm{~kg} \mathrm{ha}^{-1}$ de N, respectivamente.

Nos tratamentos que receberam $\mathrm{N}$, na camada de 0-10 cm de profundidade (Quadro 3) e na primeira amostragem de solo (Quadro 5), em outubro de 2001, foi observado maior teor de $\mathrm{Mg}$ trocável no solo. Tal fato deve-se à aplicação de 1,$0 ; 1,2 ; 1,5 ; \mathrm{e} 1,7 \mathrm{t} \mathrm{ha}^{-1}$ de calcário dolomítico em 1998, nos tratamentos com doses de $0,150,300$ e $450 \mathrm{~kg} \mathrm{ha}^{-1}$ de $\mathrm{N}$, respectivamente. O maior teor de $\mathrm{Mg}$ no solo e também o de $\mathrm{K}$, nos piquetes que receberam $\mathrm{N}$, ocorreram, inclusive, em decorrência da absorção desses nutrientes pelas raízes da gramínea em camadas mais profundas do solo e devolução destes na superfície, considerando-se que, quanto maior a dose de $\mathrm{N}$, maior é a produção vegetal e maior é a devolução de resíduos na superfície do solo, com maior enriquecimento da camada superficial. A mineralização do rebanho também pode ter contribuído para aumento do teor de $\mathrm{Mg}$ no solo, principalmente nas maiores doses de N, em razão da maior lotação animal e, conseqüentemente, da maior quantidade de dejetos que, por sua vez, contêm minerais que não foram metabolizados pelos bovinos. Como a forragem é a principal fonte de K, apresentando concentração suficiente que supre as exigências de novilhos, não é necessária a adição desse elemento no sal mineral. Por sua vez, solos com maior CTC apresentam maior quantidade de sítios de retenção de $\mathrm{K}^{+} \mathrm{e} \mathrm{Mg}^{2+}$ do solo, contribuindo para diminuição da perda desses nutrientes por lixiviação.

Detectou-se decréscimo no teor de P no solo no final do experimento, nas profundidades de 0-10 e de 10-20 cm (Quadro 4). Isso também foi observado para o teor de $\mathrm{Mg}^{2+}$, na profundidade de $0-10 \mathrm{~cm}$. Contudo, os teores de $\mathrm{Mg}^{2+}$ foram iguais nas duas épocas de amostragem, com aplicação de 0,150 e $300 \mathrm{~kg} \mathrm{ha}^{-1}$ de $\mathrm{N}$, porém, na dose de $450 \mathrm{~kg} \mathrm{ha}^{-1} \mathrm{de} \mathrm{N}$, o teor de $\mathrm{Mg}^{2+}$ foi menor no final do período experimental, em relação ao início (Quadro 5). Esses fatos podem ter ocorrido em decorrência da absorção dos nutrientes do solo pela planta. A diminuição do teor de $\mathrm{P}$ no solo ao final do experimento pode ter sido decorrente, também, da maior adsorção de fosfatos e da formação de fosfatos insolúveis de $\mathrm{Fe}$ e de $\mathrm{Al}$, que ocorrem em função da diminuição do pH (Quadro 4) (Quaggio, 2000).

Houve aumento do teor de $\mathrm{Ca}^{2+}$ no final do período experimental, em relação ao início, na profundidade 
de $20-40 \mathrm{~cm}$ (Quadro 4). Nesse sentido, os ânions $\mathrm{NO}_{3}{ }^{-}$ aplicados na superfície do solo por meio de adubações com $\mathrm{NH}_{4} \mathrm{NO}_{3}$, ou oriundos da nitrificação do amônio ou da mineralização da MO, podem ter contribuído para lixiviação do $\mathrm{Ca}^{2+}$ e do $\mathrm{K}^{+}$através do perfil do solo para a camada de $20-40 \mathrm{~cm}$.

\section{Atributos físicos do solo}

A interação foi significativa entre as doses de $\mathrm{Ne}$ as profundidades do solo para percentagem de macroporos e de microporos; quanto à densidade do solo e à resistência à penetração, não se detectou interação significativa (Quadro 6).

A percentagem de macroporos do solo diminuiu linearmente, enquanto a de microporos aumentou linearmente com a adubação nitrogenada, na profundidade de $0-5 \mathrm{~cm}$ (Quadro 6). A densidade do solo apresentou resposta quadrática ao aumento das doses de N (Quadro 6), mas a variação foi muito pequena. Essas alterações devem estar relacionadas com a maior lotação das pastagens, em decorrência do aumento de produção de forragem proporcionado pela adubação, o que resultou em maior pressão no solo causada pelo pisoteio dos animais. Bertol et al. (2000) verificaram aumento na densidade e na percentagem de microporos do solo na profundidade de $0-5 \mathrm{~cm}$ de 1,1 para $1,4 \mathrm{~kg} \mathrm{dm}^{-3}$ e de 34,3 para $39,3 \%$, respectivamente, e diminuição na percentagem de macroporos de 7,8 para $6,4 \%$, quando aumentaram a lotação animal de $1.216 \mathrm{~kg} \mathrm{ha}^{-1} \mathrm{dia}^{-1}$ de peso corporal para $2.263 \mathrm{~kg} \mathrm{ha}^{-1} \mathrm{dia}^{-1}$ (oferta de forragem de $16 \mathrm{e} 4 \%$ do peso corporal), respectivamente, em um Cambissolo Álico (300 g kg-1 de argila, $360 \mathrm{de}$ areia e 340 de silte). Por outro lado, a resposta quadrática da densidade do solo às doses de $\mathrm{N}$ pode também ser explicada como efeito quadrático da adubação nitrogenada no teor de matéria orgânica do solo na camada de 0 a $10 \mathrm{~cm}$ de profundidade, o que foi observado neste experimento (Quadro 3), pois na maior dose de $\mathrm{N}$ prevaleceu o efeito da matéria orgânica na melhoria da estrutura do solo.

A percentagem de poros totais não apresentou variação em função da adubação nitrogenada e da profundidade de amostragem (Quadro 6), o que se deve à compensação do aumento da percentagem de microporos pela diminuição de macroporos.

Quando o teor de água do solo era em média de $90 \mathrm{~g} \mathrm{~kg}^{-1}$ (janeiro de 2002), não foi observado efeito da adubação nitrogenada na penetrabilidade (Quadro 6), e os resultados obtidos (médias de 1,65 a 2,51 MPa) não eram restritivos à produtividade, pois, segundo Semmel et al. (1990), apenas valores maiores que 2,5 $\mathrm{MPa}$ prejudicam o crescimento de gramíneas forrageiras. Quando o teor de umidade diminuiu para cerca de $20 \mathrm{~g} \mathrm{~kg}^{-1}$, houve (fevereiro de 2002), como esperado, aumento da resistência à penetração, atingindo valores de 7,0;2,9;4,5; e 4,9 MPa na camada de $0-5 \mathrm{~cm}$, respectivamente, nos tratamentos que receberam as doses de $0,150,300$ e $450 \mathrm{~kg} \mathrm{ha}^{-1}$ de $\mathrm{N}$. A maior resistência à penetração no tratamento que não recebeu adubação nitrogenada pode ser explicada pela menor cobertura vegetal, que, por sua vez, resulta em maior impacto do pisoteio animal (Mello, 2002) e menor umidade do solo.

$\mathrm{O}$ menor valor de resistência do solo à penetração obtido na dose de $150 \mathrm{~kg} \mathrm{ha}^{-1}$ de N (2,9 MPa com teor de água $19 \mathrm{~g} \mathrm{~kg}^{-1}$ ) pode ser decorrente do maior crescimento radicular da gramínea, comparado com as demais doses, na camada de $0-10 \mathrm{~cm}$ de profundidade. Nesse mesmo experimento, Sarmento et al. (2008) obtiveram densidade de raízes de 3.748,

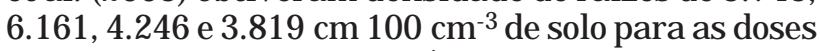
de $0,150,300$ e $450 \mathrm{~kg} \mathrm{ha}^{-1}$ de $\mathrm{N}$, respectivamente. $\mathrm{O}$ crescimento do sistema radicular das plantas proporciona estruturação do solo, que reequilibra sua porosidade e reduz sua densidade (Silva \& Mielniczuk, 1997). A maior lotação das pastagens nas doses $300 \mathrm{e}$ $450 \mathrm{~kg} \mathrm{ha}^{-1}$ de $\mathrm{N}$ também contribuiu para maior resistência do solo à penetração, quando comparada com a dose $150 \mathrm{~kg} \mathrm{ha}^{-1} \mathrm{de} \mathrm{N}$.

Observou-se maior densidade e percentagem de microporos na profundidade de $0-5 \mathrm{~cm}$ do que na de 5-10 cm, com exceção das áreas não adubadas, nas quais a microporosidade do solo não diferiu entre as profundidades estudadas. A percentagem de macroporos foi maior na profundidade de $5-10 \mathrm{~cm}$, em comparação com a de $0-5 \mathrm{~cm}$, nas doses de 300 e $450 \mathrm{~kg} \mathrm{ha}^{-1}$ de N (Quadro 6). Segundo Corrêa \& Reichardt (1995) e Bertol et al. (2000), a camada do solo mais alterada pelo pastejo é a superficial.

A resistência do solo à penetração foi maior na profundidade de $10-20 \mathrm{~cm}$, em relação à de $20-40 \mathrm{~cm}$, e essas duas profundidades apresentaram resistências maiores que a camada de $0-10 \mathrm{~cm}$, quando o solo apresentava teor de água de $90 \mathrm{~g} \mathrm{~kg}^{-1}$ (Quadro 6). Uma vez que a camada do solo mais alterada pelo pisoteio dos animais é a superficial (Corrêa \& Reichardt, 1995), os resultados obtidos não parecem ter sido provocados diretamente pelo pisoteio animal, e sim causados pelas operações mecânicas de aração e gradagem ocorridas entre os anos de 1993 e 1995 para o cultivo de sorgo e de aveia, bem como para implantação do capim-milênio. A exposição do solo a ciclos de umedecimento e secagem e seu revolvimento contínuo contribuem para o adensamento, pois esses fatores favorecem o aumento de argila dispersa em água nas camadas superficiais, que obstruem os poros do solo em camadas subsuperficiais (Costa \& Abrahão, 1996). A maior resistência à penetração na camada de $20-40 \mathrm{~cm}$ de profundidade, quando comparada com a de $0-10 \mathrm{~cm}$, deve estar relacionada também com a presença de um horizonte B textural (gradiente textural com enriquecimento de argila no horizonte B), que é uma característica dos solos Podzólicos (Oliveira et al., 1992), os quais correspondem aos Argissolos na nova classificação dos solos (Embrapa, 1999). 
Quadro 6. Atributos físicos do solo de pastagens de capim-milênio em função das diferentes profundidades e das doses de nitrogênio

\begin{tabular}{|c|c|c|c|c|c|c|c|}
\hline \multirow{2}{*}{ Profundidade } & \multicolumn{5}{|c|}{ Dose de N $\left(\mathrm{kg} \mathrm{ha}^{-1}\right)$} & \multirow{2}{*}{ Equação } & \multirow{2}{*}{$\mathbf{R}^{2}$} \\
\hline & $\mathbf{0}$ & 150 & 300 & 450 & Média & & \\
\hline $\mathrm{cm}$ & \multicolumn{5}{|c|}{ Densidade $\left(\mathrm{kg} \mathrm{dm}^{-3}\right)$} & & \\
\hline $0-5$ & 1,62 & 1,64 & 1,68 & 1,64 & $1,64 \mathrm{a}^{(1)}$ & - & - \\
\hline $5-10$ & 1,60 & 1,62 & 1,63 & 1,61 & $1,62 \mathrm{~b}$ & - & - \\
\hline \multirow[t]{2}{*}{ Média } & 1,61 & 1,63 & 1,66 & 1,62 & - & $\hat{y}=1,61+0,0003 x-0,0000007 x^{2}$ & $0,77^{*}$ \\
\hline & \multicolumn{5}{|c|}{ Percentagem de macroporo (\%) } & & \\
\hline $0-5$ & $16,6 \mathrm{a}$ & $15,8 \mathrm{a}$ & $11,5 \mathrm{~b}$ & $11,6 b$ & 13,9 & $\hat{y}=16,8-0,0129 x$ & $0,85^{*}$ \\
\hline $5-10$ & $17,4 \mathrm{a}$ & $17,5 \mathrm{a}$ & $16,2 \mathrm{a}$ & $16,9 \mathrm{a}$ & 17,0 & $\mathrm{~ns}$ & - \\
\hline \multirow[t]{2}{*}{ Média } & 17,0 & 16,7 & 13,9 & 14,2 & - & - & - \\
\hline & \multicolumn{5}{|c|}{ Percentagem de microporo (\%) } & & \\
\hline $0-5$ & $18,2 \mathrm{a}$ & $19,1 \mathrm{a}$ & $21,8 \mathrm{a}$ & $23,1 \mathrm{a}$ & 20,6 & $\hat{y}=17,9-0,0116 x$ & $0,96^{*}$ \\
\hline $5-10$ & $17,2 \mathrm{a}$ & $16,5 \mathrm{~b}$ & $18,6 \mathrm{~b}$ & $18,0 \mathrm{~b}$ & 17,6 & $\mathrm{~ns}$ & - \\
\hline \multirow{2}{*}{ Média } & 17,7 & 17,8 & 20,2 & 20,6 & - & - & - \\
\hline & \multicolumn{5}{|c|}{ Percentagem de poros totais (\%) } & & \\
\hline $0-5$ & 34,8 & 33,9 & 33,3 & 34,7 & 34,2 & - & - \\
\hline $5-10$ & 34,7 & 34,0 & 34,8 & 34,8 & 34,6 & - & - \\
\hline \multirow[t]{2}{*}{ Média } & 34,8 & 34,0 & 34,1 & 34,8 & & $\mathrm{~ns}$ & \\
\hline & \multicolumn{5}{|c|}{ Resistência à penetração (MPa) } & & \\
\hline $0-10$ & 1,76 & 1,62 & 1,65 & 1,56 & $1,65 \mathrm{c}$ & - & - \\
\hline $10-20$ & 2,68 & 2,47 & 2,48 & 2,40 & $2,51 \mathrm{a}$ & - & - \\
\hline $20-40$ & 2,01 & 2,34 & 2,21 & 2,19 & $2,19 \mathrm{~b}$ & - & - \\
\hline Média & 2,15 & 2,14 & 2,11 & 2,05 & & $\mathrm{~ns}$ & - \\
\hline
\end{tabular}

${ }^{(1)}$ Médias seguidas por letras diferentes, numa mesma coluna, diferem entre si a $5 \%$ pelo teste de Tukey. Os coeficientes de variação para a densidade do solo, a percentagem de macroporos e de microporos e para a resistência do solo à penetração foram de $2,15,11$ e $11 \%$, respectivamente.*: Significativo a $5 \%$ pelo teste $\mathrm{F}$ e ns: não-significativo.

\section{CONCLUSÕES}

1. Adubação nitrogenada em pastagens de Panicum maximum cv. IPR-86 Milênio, durante cinco anos, proporciona incremento nos teores de $\mathrm{MO}$ e nos valores de CTC no solo.

2. O maior pisoteio dos animais, em função do aumento da produção de forragem decorrente da adubação nitrogenada, resulta em aumento da percentagem de microporos e diminuição da de macroporos, na camada de $0-5 \mathrm{~cm}$.

\section{LITERATURA CITADA}

BERTOL, I.; ALMEIDA, J.A.; ALMEIDA, E.X. \& KURTZ, C. Propriedades físicas do solo relacionadas a diferentes níveis de oferta de forragem de capim-elefante-anão cv. Mott. Pesq. Agropec. Bras., 35:1047-1054, 2000.
BOHNEN, H. Acidez do solo: Origem e correção. In: KAMINSKI, J., coord. Uso de corretivos da acidez do solo no plantio direto. Pelotas, SBCS-Núcleo Regional Sul, 2000. p.9-20. (Boletim Técnico, 4)

BRAZ, S.P.; NASCIMENTO Jr., D.; CANTARUTTI, R.B.; REGAZZI, A.J.; MARTINS, C.E.; FONSECA, D.M. \& BARBOSA, R.A. Aspectos quantitativos do processo de reciclagem de nutrientes pelas fezes de bovinos sob pastejo em pastagem de Brachiaria decumbens na Zona da Mata de Minas Gerais. R. Bras. Zootec., 31:858-865, 2002.

CORRÊA, J.C. \& REICHARDT, K. Efeito do tempo de uso das pastagens sobre as propriedades de um Latossolo Amarelo da Amazônia Central. Pesq. Agropec. Bras., 20:107-114, 1995.

CORSI, M. \& NUSSIO, L.G. Manejo do capim elefante: Correção e adubação do solo. In: SIMPÓSIO SOBRE MANEJO DA PASTAGEM, 10., Piracicaba, 1993. Anais. Piracicaba, FEALQ, 1993. p.87-116. 
COSTA, L.M. \& ABRAHÃO, W.A.P. Compactação e adensamento de solos relacionados às propriedades químicas, físicas e sedimentológicas. In: ALVAREZ V., V.H.; FONTES, L.E.F. \& FONTES, M.P.F., eds. O solo nos grandes domínios morfoclimáticos do Brasil e o desenvolvimento sustentado. Viçosa, MG, Sociedade Brasileira de Ciência do Solo, 1996. p.429-443.

EMPRESA BRASILEIRA DE PESQUISA AGROPECUÁRIA EMBRAPA. Centro Nacional de Pesquisa de Solos. Manual de métodos de análise de solo. 2.ed. Rio de Janeiro, 1997. 212p. (Documentos, 1)

EMPRESA BRASILEIRA DE PESQUISA AGROPECUÁRIA EMBRAPA. Sistema brasileiro de classificação de solos. 2.ed. Rio de Janeiro, Centro Nacional de Pesquisa de Solos, 1999. $412 \mathrm{p}$

HARRISON, D.F.; CAMERON, K.C. \& McLAREN, R.G. Effects of subsoil loosening on soil physical properties, plant root growth, and pasture yield. N. Z. J. Agric. Res., 37:559567, 1994.

HILLESHEIM, A. \& CORSI, M. Capim-elefante sob pastejo. II. Fatores que afetam as perdas e utilização de matéria seca. Pesq. Agropec. Bras., 25:1233-1246, 1990.

LUGÃO, S.B. \& ABRAHÃO, J.J.S. Relatório técnico do programa de forragicultura. Londrina, IAPAR, 1995. 20p.

LUGÃO, S.M.B. Produção de forragem e desempenho animal em pastagens de Panicum maximum Jacq. (acesso BRA006998) adubadas com $\mathrm{N}$ na região noroeste do Paraná Jaboticabal, Universidade Estadual Paulista, 2001. 151p. (Tese de Doutorado)

MAPFUMO, E.; CHANASYK, D.S.; BARON, V.S. \& NAETH, M.A. Grazing impacts on selected soil parameters under short-term forage sequences. J. Range Manag., 53:466470,2000 .

MELLO, N.A. Degradação física dos solos sob integração lavoura pecuária. In: ENCONTRO DE INTEGRAÇ̃̃O LAVOURA-PECUÁRIA NO SUL DO BRASIL, 1., Pato Branco, 2002. Anais. Pato Branco, CEFET-PR, 2002. p.4360 .

MOTT, G.O. \& LUCAS, H.L. The design, conduct and interpretation of grazing trials in cultived and improved pastures. In: INTERNATIONAL GRASSLAND CONGRESS, 6., State College, 1952. Proceedings. State College, State College Press, 1952. p.1380-1385.
OLIVEIRA, J.B.; JACOMINE, P.K. \& CAMARGO, M.N. Classes gerais de solos no Brasil: Guia auxiliar para seu reconhecimento. Jaboticabal, FUNEP, 1992. 201p.

QUAGGIO, J.A. Acidez e calagem em solos tropicais. Campinas, Instituto Agronômico, 2000. 111p.

RAIJ, B. van.; QUAGGIO, J.A.; CANTARELLA, H.; FERREIRA, M.E.; LOPES, A.S. \& BATAGLIA, O.C. Análise química do solo para fins de fertilidade. Campinas, Fundação Cargill, 1987. 170p.

SARMENTO, P.; RODRIGUES, L.R.A.; LUGÃO, S.M.B.; CRUZ, M.C.P.; CAMPOS, F.P.; FERREIRA, M.E. \& OLIVEIRA, R.F. Sistema radicular do Panicum maximum Jacq. cv. IPR-86 Milênio adubado com nitrogênio e submetido à lotação rotacionada. R. Bras. Zootec., 37:27-34, 2008.

SARMENTO, P.; RODRIGUES, L.R.A.; LUGÃO, S.M.B.; CRUZ M.C.P.; CAMPOS, F.P. \& FERREIRA, M.E. Respostas agronômicas e morfológicas de Panicum maximum Jacq. cv. IPR-86 Milênio, sob pastejo, à adubação nitrogenada. B. Ind.Animal, 62:333-346, 2005.

SAS INSTITUTE. Property software release 8. Cary, 1999. $956 \mathrm{p}$.

SEMMEL, H.; HORN, R.; HELL, U.; DEXTER, A.R. \& SCHULZE, E.D. The dynamics of soil aggregate formation and the effect on soil physical properties. Soil Technol., 3:113-129, 1990.

SILVA, A.P.; IMHOFF, S.; TORMENA, C.A. \& TAKAHAMA, R.S. Qualidade física de solos sob sistemas intensivos de pastejo rotacionado. In: SIMPÓSIO SOBRE MANEJO DA PASTAGEM, 19., Piracicaba, 2002. Anais... Piracicaba, FEALQ, 2002. p.79-99

SILVA, I.F. \& MIELNICZUK, J. Ação do sistema radicular de plantas na formação e estabilização de agregados do solo. R. Bras. Ci. Solo, 21:113-117, 1997.

WHEELER, M.A.; TRLICA, M.J.; FRASIER, G.W. \& REEDER, J.D. Seasonal grazing affects on soil physical properties of a montane riparian community. J. Range Manag., 55:49-56, 2002.

WHITEHEAD, D.C. Grassland nitrogen. Wallingford, CAB International, 1990. 397p 